\title{
User Experience on BM Year 2 Mobile-based Learning Application for Alpha Generation
}

\author{
https://doi.org/10.3991/ijim.v15i06.20639 \\ Azizah Che Omar $(\bowtie)$ \\ Universiti Utara Malaysia, Sintok, Malaysia \\ omarche.az@yandex.com \\ Nurulnadwan Aziz \\ Universiti Teknologi MARA Dungun, Terengganu, Malaysia \\ Mohd Adib Abd Muin \\ Universiti Utara Malaysia, Kedah, Malaysia
}

\begin{abstract}
This paper reports the ongoing project related to the development of mobile-based learning application particularly for Alpha Generations who studies in international school. Due to the advancement of digital technologies, Alpha Generations tend to interact with mobile device compared to conventional environment as they were born in the century of digital age. This includes their learning activities. In Malaysia, expert in language literacy particularly Malay language is compulsory for all including foreigner students who learn in international school. As the mobile-based learning application could provide attractive and interactive interaction compared to conventional teaching method, providing children with additional mobile-based learning tool could facilitates them to have their own active learning experience. This study found that this is the research gap that should be fill in to ensure children in international school able to literate in Malay Language similar to mainstream student. Therefore, mobile-based learning application called BM Year 2 has been developed and evaluated. The proposed application also has been discussed in the previous paper which involves expert evaluation. To ensure the proposed application could fulfill the actual users' needs, user experience testing has been carried out and discusses in this paper. They are tested in terms of layout and design, functionality, and user's satisfaction. A set of questionnaires has been set up and distributed to the actual users upon they use the proposed mobile-based learning application BM Year 2. Overall, the empirical findings found that theBM Year 2 able to evoke positive learning experience to the actual users.
\end{abstract}

Keywords - Children Computer Interaction, Interaction Design, Mobile-based Learning Application, User -Centered Design Approach, User Experience, Alpha Generation 


\section{Introduction}

The lifestyle of Alpha Generation is parallel with the advancement of digital age. The development of digital technologies has influence them to adapt the use of digital mobile device in their daily life routine including their learning activities [2][3][1]. From that a lot of mobile-based learning application has been designed and develop to fulfill their learning needs [4-8]. In the context of Malaysian scenario learning through mobile-based application has been researched and proposed since the past 15 years ago and is it continue with the new ideas based on the user needs. All of them have their own target users and objective.

In the mainstream education system, it is compulsory for the students to expert in language literacy particularly in Malay Language. This education system is also implemented to the international school system where all the students including foreigner have to expert in Malay Language. To fulfill the identified research gap, this study has proposed a mobile-based learning application called BM Year 2 for Alpha Generation who studied in international school. It has been developed by utilizing the user-centered design (UCD) approach and evaluation has been conducted through expert review method. Hence, the main aim of this paper is to evaluate the user experience of BM Year 2 mobile-based learning application in terms of layout and design, functionality, and user satisfaction.

To achieve the main objective, the research methodology of the study was discussed in the next section.

\section{Methodology}

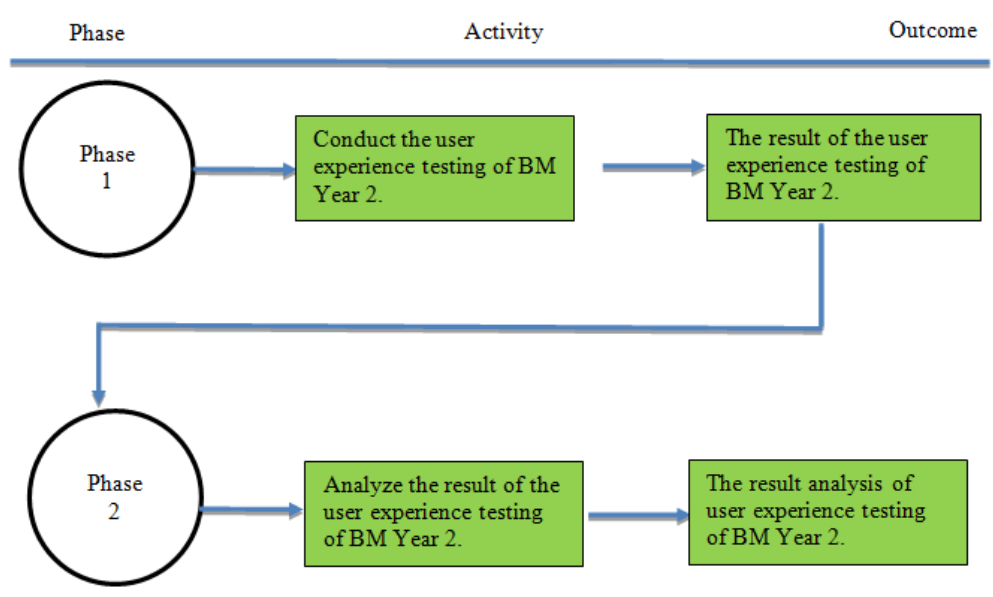

Fig. 1. Research activities of the study

The research methodology begins with phase one by conducting the user experience testing of BM Year 2 mobile application. The respondents involve are the children from international school. The closed-ended questionnaires were given to the respondents 
upon complete using the prototype. The outcome of this phase is the result of the user experience testing.

The second phase of the study is result analysis which means the gathered result in phase one were analysed and presented at this stage.

\section{The Proposed Prototype}

The BM Year 2 mobile learning application has been developed by utilizing Adobe Photoshop to design the character and objects and Adobe Flash with action script 3.0 to integrate the interaction concept. The content of the proposed prototype has been design based on the Unicode Consortium Guidelines as well as other relevant studies related to mobile-based learning application. Multimedia elements which are audio, text, graphic, and animation were incorporate to trigger the interactive learning concept.

Figure 2 until Figure 8 displays the screenshot of the BM Year 2 mobile-based learning application. Upon user click the start button they will be navigated to menu page which provides two main buttons, which are e-Dictionary and Quiz. BM Year 2 mobile-based learning application enable the user to learn vocal, consonant, syllable, and phrase and pronunciation. Meanwhile in the Quiz page the students can test their understandable of vocal, consonant, syllable, and phrase and pronunciation.

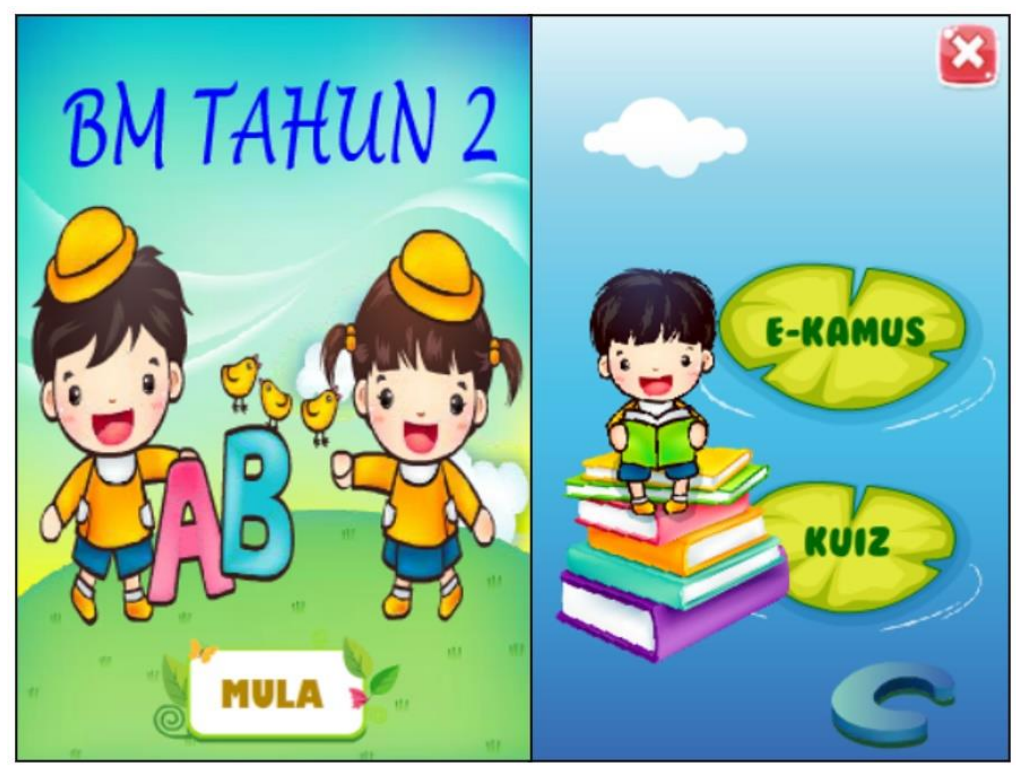

Fig. 2. Homepage 


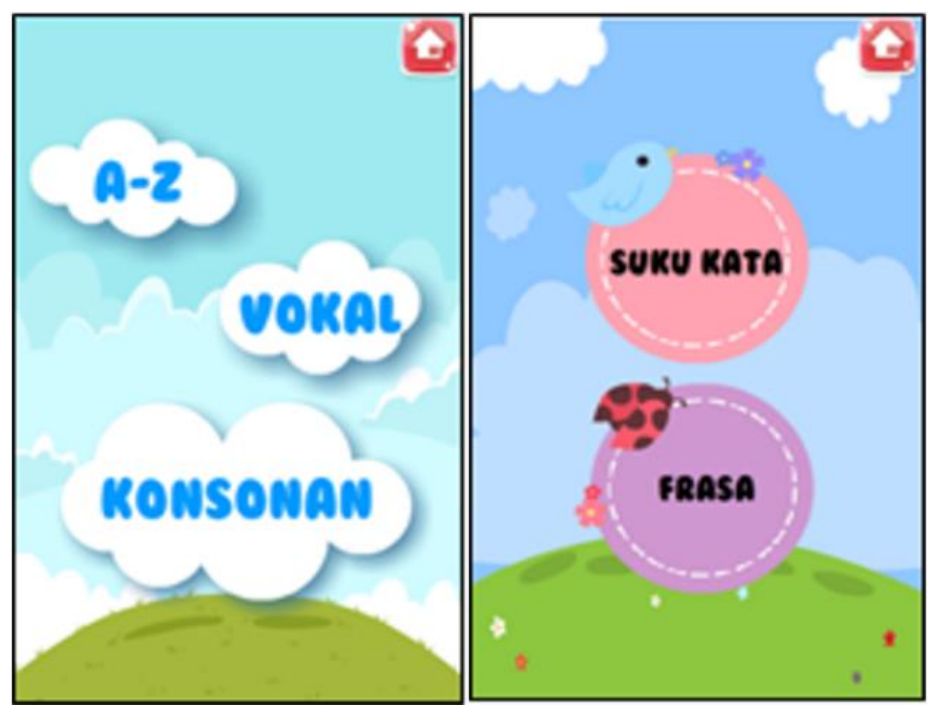

Fig. 3. Sub menu page

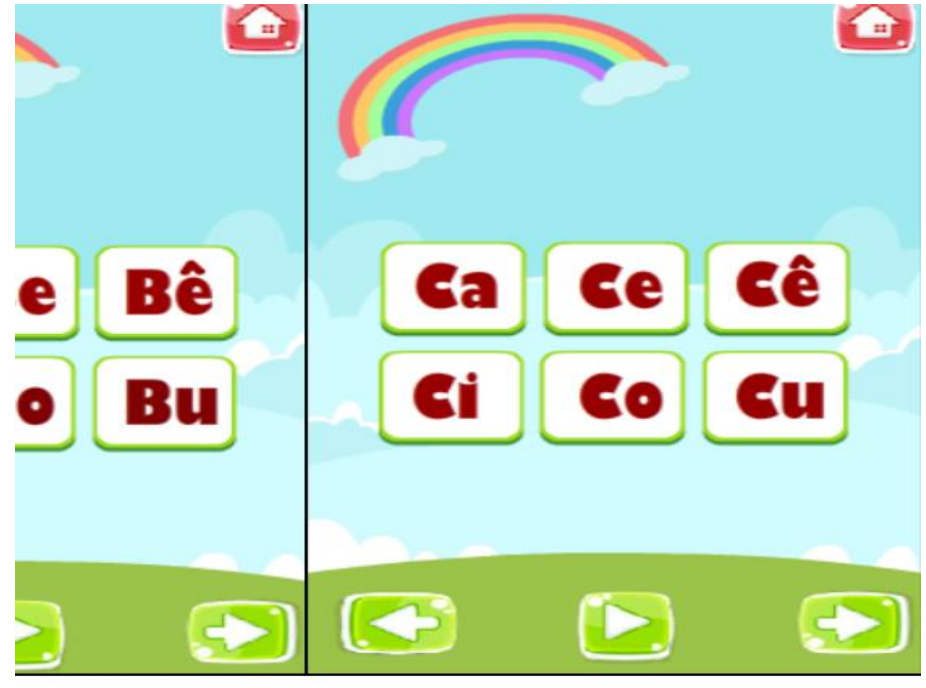

Fig. 4. Syllable page 


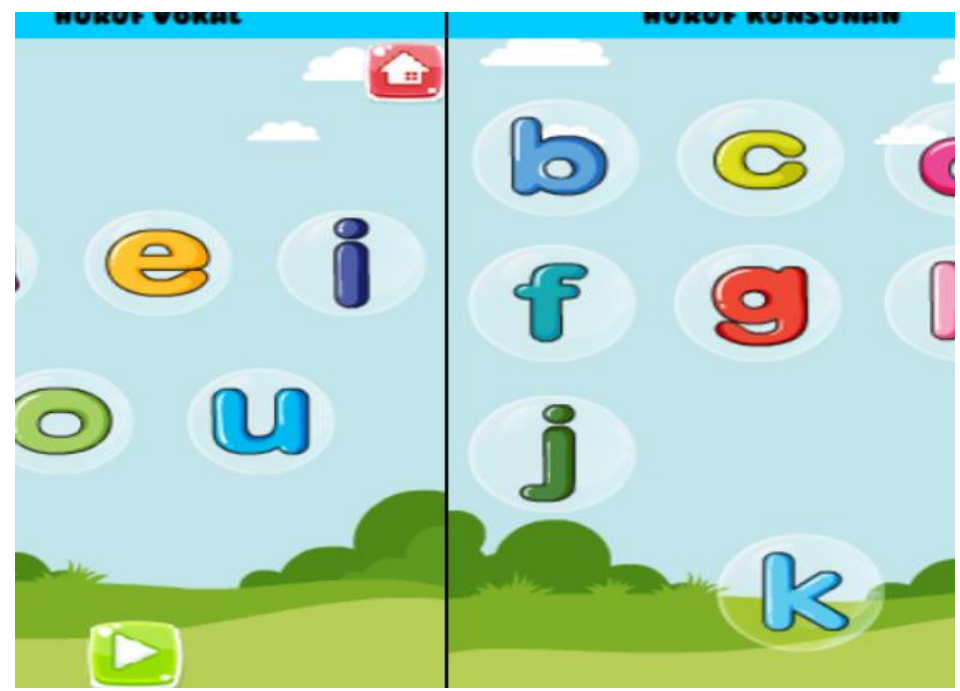

Fig. 5. Vocal and consonant page

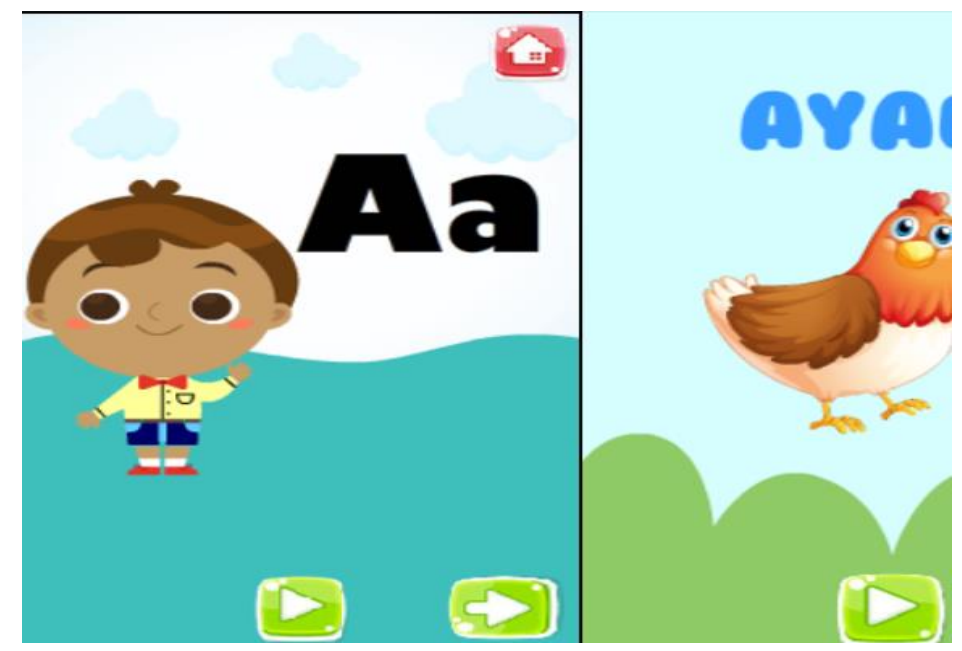

Fig. 6. Alphabet and phonics page 


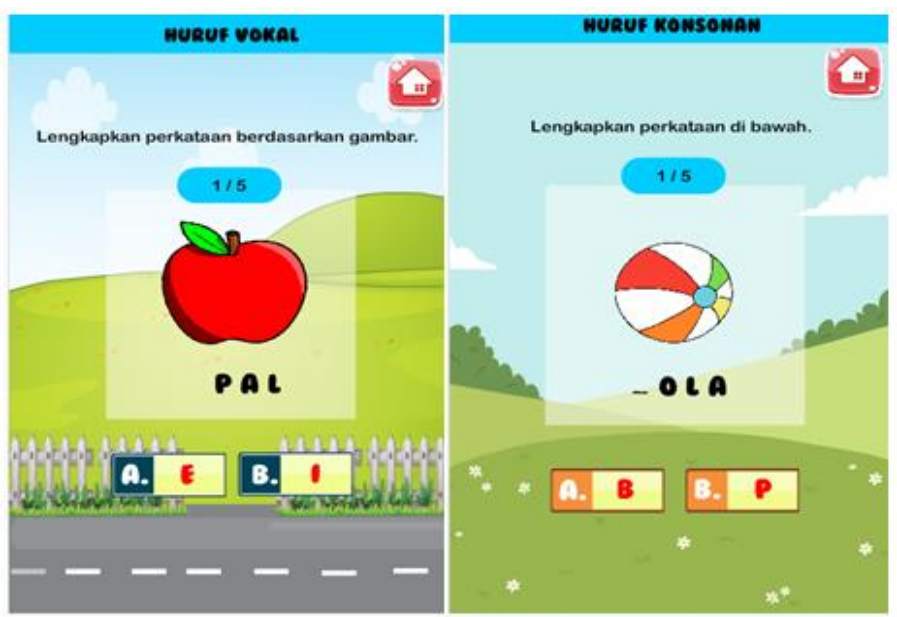

Fig. 7. Vocal and consonant quiz page

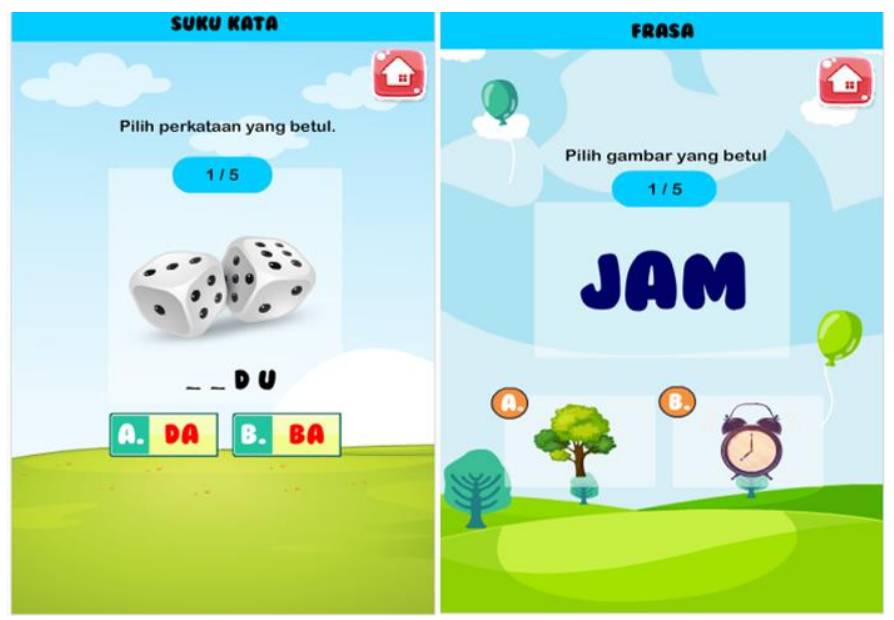

Fig. 8. Quiz page for syllable and phrase

\section{$4 \quad$ Result and Discussion}

The section presents the result gathered from the user experience testing which has been analysed in terms of layout and design, functionality, and user's satisfaction.

\subsection{Demographic profile}

The user experience testing was conducted with 11 students of year 2 in Universiti Utara Malaysia International School (UUMIS); 8 respondents $(72.7 \%$ ) are male 
meanwhile the remaining 3 respondents (27.3\%) are female. Figure 9 illustrates the percentage of the demographic profile.

\section{Gender}

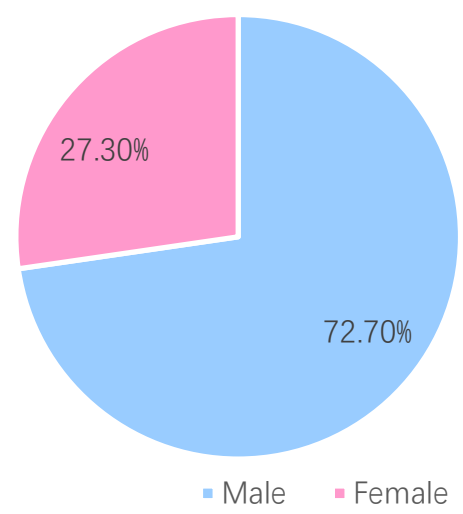

Fig. 9. Demographic profile of the respondents

\subsection{Layout and design}

This section consists of five questions related to layout and design.

Table 1 listed the questions.

\begin{tabular}{|c|l|}
\hline No. & \multicolumn{1}{|c|}{ Questions } \\
\hline Q1 & Does the arrangement of the buttons are suitable? \\
\hline Q2 & Does the use of colours are suitable? \\
\hline Q3 & Does the text is easy to understand? \\
\hline Q4 & Does the animation is interesting? \\
\hline Q5 & Does the overall design is eye-catching? \\
\hline
\end{tabular}

The results indicates that all the 11 respondents agreed that with arrangement of button, the suitability of the colours, the understandable text, the interesting animation and the overall design of is eye-catching except for the question (Q3) two of the responded were disagreed. Figure 10 display the results. 


\section{Layout and Design}

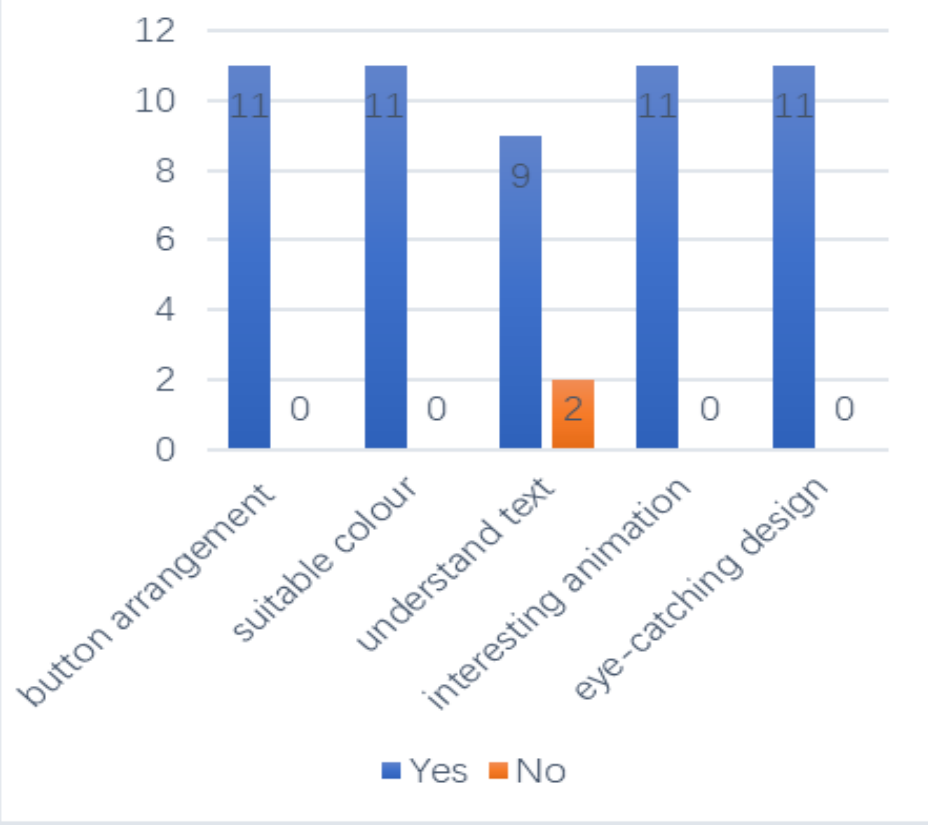

Fig. 10.Layout and design analysis

\subsection{Functionality}

In terms of the functionality five questions were provided to the user to express their learning experience. There are listed in Table 2.

\begin{tabular}{|c|l|}
\hline No. & \multicolumn{1}{|c|}{ Questions } \\
\hline Q1 & Does the provided sounds is suitable? \\
\hline Q2 & Does the provided buttons are well-function? \\
\hline Q3 & Does the application react quickly based on the request? \\
\hline Q4 & Is there any error occurred while using the application? \\
\hline Q5 & Does the overall application perform smoothly? \\
\hline
\end{tabular}

It is reported that majority of the respondents say "yes” to the Q1 until Q5 except for question $(\mathrm{Q} 4)$ one of the respondents disagreed (Fig. 11). 


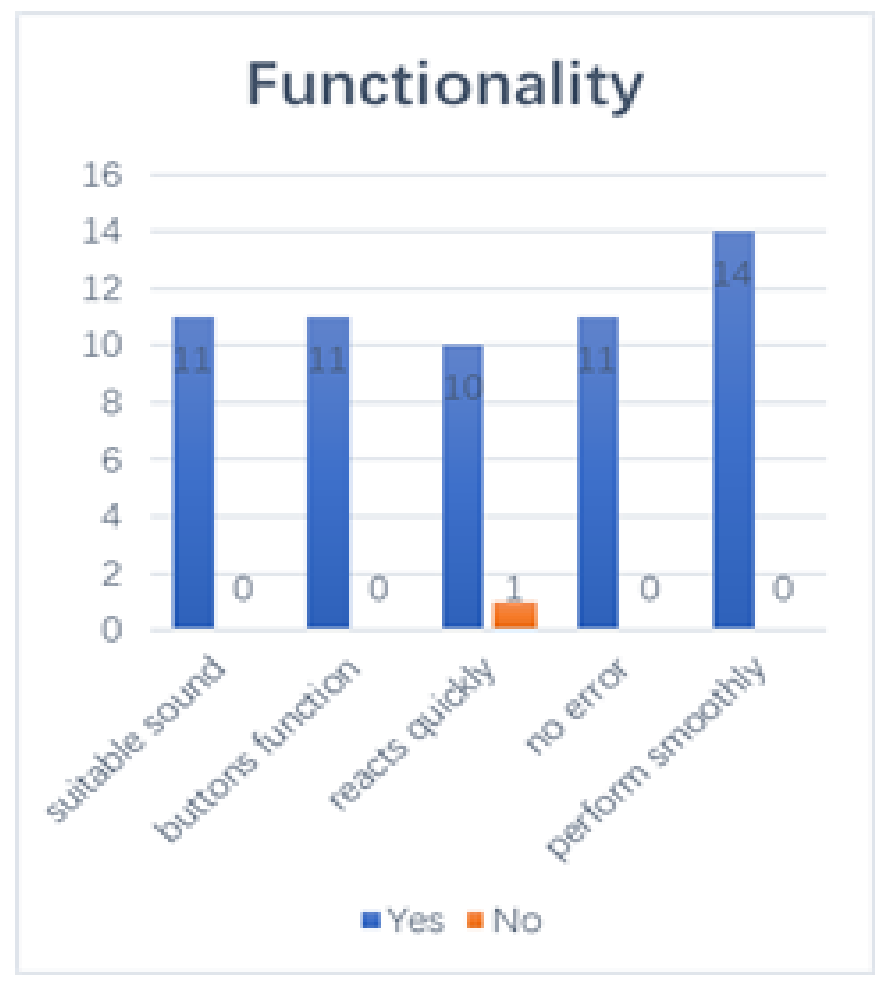

Fig. 11.Functionality analysis

\subsection{User's satisfaction}

In terms of user's satisfaction, five question were asked as listed in Table 1.

\begin{tabular}{|c|l|}
\hline No. & \multicolumn{1}{|c|}{ Questions } \\
\hline Q1 & Do you like the BM Year 2 mobile application? \\
\hline Q2 & Does the application is simple to understand and easy to use? \\
\hline Q3 & Is the BM Year 2 facilitate the students to learn effectively? \\
\hline Q4 & Does the BM Year 2 provide clear information? \\
\hline Q5 & Does the BM Year 2 is pleasant to use? \\
\hline
\end{tabular}

As demonstrates in Figure 12, most of the respondents provide positive feedback except for the Q3 and Q4 one of the respondents disagreed. 


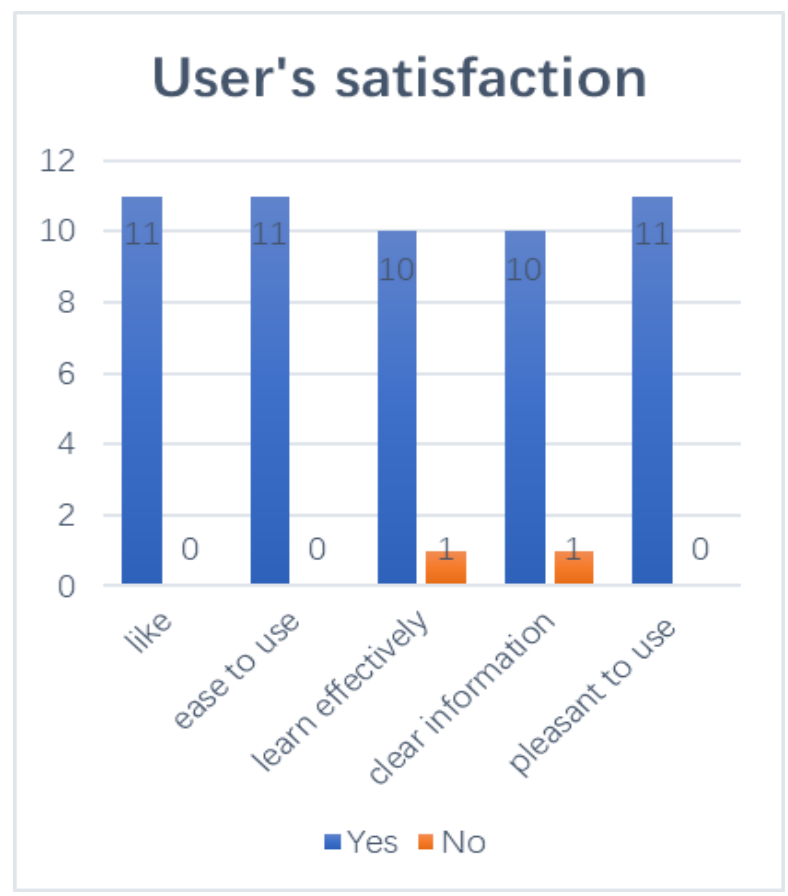

Fig. 12.User's satisfaction analysis

Based on the user experience testing that has been conducted, the results indicate that most of the respondents satisfied with the BM Year 2 mobile learning application. The setting of the testing in the classroom makes them feel comfortable to enjoy the prototype. More important they also able to learn without guidance from their instructors. This ensure that the proposed BM Year 2 mobile-based learning application has successfully provides flexibility learning environment to the intended users.

\section{Conclusion}

Overall, this study achieves the main aim which is to test the user experience of BM Year 2 mobile-based learning application. The results reported that the proposed BM Year 2 mobile-based learning application able to evoke the positive learning experience to the target users. As the learning language literacy is important to the students since they was child therefore this study can be as a guideline for the school institutions to promote flexible learning environment.

\section{Acknowledgement}

This study would like to thank you to the Research and Innovation Management Centre (RIMC), Universiti Utara Malaysia for funding this study through University 
Grant Scheme. Also, to the FRGS-RACER grant scheme provided by Ministry of Education, Malaysia. It is registered with SO Code 14434. In addition, special thank you to our Research Assistant Lai Sek Yun and Fatehah Mohd Wazir Muhammad Ibrahim for their contributions particularly in terms of the prototype design and development. The last but not least, a million thank you also goes to the experts from School of Multimedia Technology and Communication (SMMTC), Universiti Utara Malaysia and teachers from UUM International School.

\section{$7 \quad$ References}

[1] Aziz, N., Che Omar, A., Mutalib, A.A., Ahmad, S.Z. Muin, M.A. \& Annamalai, S. (2020). Uncovering the needs for a hybridized interaction design model for sign language learning through experts' feedback. Journal Of Physics: Conference Series. 1529(42102): 1 - 10. https://doi.org/10.1088/1742-6596/1529/4/042102

[2] Ghavifekr, S. \& Rosdy, W.A.W. (2015). Teaching and learning with technology: Effectiveness of ICT integration in schools. International Journal of Research in Education and Science (IJRES), 1(2): 175-191. https://doi.org/10.21890/ijres.23596

[3] Mayer, R.E. (2020). Where is the learning in mobile technologies for learning? Contemporary Educational Psychology, 60(2020): 1-3. https://doi.org/10.1016/j.cedpsych. $\underline{2019.101824}$

[4] Cerezoa, R., Vicente Calderón, V., \& Romero, C. (2019). A holographic mobile-based application for practicing pronunciation of basic English vocabulary for Spanish speaking children. International Journal of Human Computer Studies, 13-25. https://doi.org/10. $\underline{1016 / j . i j h c s .2018 .11 .009}$

[5] Choi G. W., Land S. M., \&Zimmerman H. T. (2018). Investigating children's deep learning of the tree life cycle using mobile technologies. Computers in Human Behavior, $470-479$. https://doi.org/10.1016/j.chb.2018.04.020

[6] Ciezaa, E. \&Lujan, D. (2018). Educational Mobile Application of Augmented Reality Based on Markers to Improve the Learning of Vowel Usage and Numbers for Children of a Kindergarten in Trujillo. Procedia Social Science. 130 (2018): 352-358. https://doi.org/10.1016/j.procs.2018.04.051

[7] Skiada, R., Soroniati, E., Anna Gardeli, A. \& Zissis, D. (2014). EasyLexia: A Mobile Application for Children with Learning Difficulties. Procedia Computer Science. 27 (2014): 218- 228. https://doi.org/10.1016/j.procs.2014.02.025

[8] Lopez-Faican L., \& Jaen, J. (2020). Emo Find AR: Evaluation of a mobile multiplayer augmented reality game for primary school children. Computers and Education, 149 (2020): 1-20. https://doi.org/10.1016/j.compedu.2020.103814

\section{Authors}

Azizah Che Omar is a Senior Lecturer at School of Multimedia Technology and Communication (SMMTC), College of Arts and Science, Universiti Utara Malaysia (UUM). She is actively involved in research and publication, both internationally and nationally. Her research interests are in Design Research, Multimedia Learning, Media, Interaction Design, Affective Computing, Assistive Technology and Interactive 
Advertising. She has published more than 18 journals and 20proceedings. She can be contacted at omarche.az@yandex.com

Ts. Dr. Nurulnadwan Aziz is a Senior Lecturer at Universiti Teknologi MARA Cawangan Terengganu. Currently she has been appointed as Coordinator of Research Management Unit, Department of Research and Industrial Linkages, Universiti Teknologi MARA Cawangan Terengganu. Her research area is Multimedia Computing and experts in Human Computer Interation, Interaction Design, Augmented Reality, Affective Computing, and Assistive Technology. She also has experience as Guest Editor for high impact journals (SCOPUS and WoS) including International Journal of Integrated Engineering (IJIE) and Asean Journal University Education (AJUE). Most of her research articles has been published by the prestigious publishers such as Springer and IEEE. She has won several research grants such as FRGS and RCF. She also is an active member of IEEE Computer Society and Malaysian Board of Technologies (MBOT). She can be contacted at: nurulnadwan@uitm.edu.my

Mohd Adib Abd Muin is a Senior Lecturer at Islamic Business School (IBS), College of Business, Universiti Utara Malaysia (UUM). Before joining UUM, he worked as an Assistant Manager at Bank Islam (M) Bhd under Automobile Financing Department. He also involved in the research related to Muamalat, Islamic Social Entrepreneurship and Islamic Finance and Banking. Email mohdadib@uum.edu.my

Article submitted 2020-11-19. Resubmitted 2021-01-25. Final acceptance 2021-01-26. Final version published as submitted by the authors. 